\title{
Caring and Curing by Mixing Information and Emotions in Orphan Diseases Websites: A Twofold Analysis
}

\author{
Maria Cristina Caratozzolo, Enrica Marchigiani, Oronzo Parlangeli, \\ and Marcella Zaccariello \\ University of Siena, Communication Sciences Department, \\ Via Roma, 56, 53100 Siena, Italy \\ cristina.caratozzolo@polimi.it, \\ \{marchigiani, parlangeli\}@unisi.it, \\ mzaccariello@virgilio.it
}

\begin{abstract}
The study reported in this article was structured as a first step in planning guidelines to design effective internet sites for Associations dealing with rare diseases. The Authors used a two-stage analysis: first, they carried out an analysis of the websites of a sample of Italian Associations on rare diseases and then they did an interview survey to identify the objectives and needs of those organizations. Results indicate that two different kinds of organizations do exist and suggest possibilities for developing guidelines aimed at improving their websites.
\end{abstract}

Keywords: Rare and orphan diseases, affective communication, patients' associations, website, usability.

\section{Introduction}

Orphan diseases include rare and neglected diseases. The two classes of pathologies have in common the fact that development and production of specific drugs are not profitable for the major pharmaceutical corporations (often referred to as "big Pharma"): that is why they are both named "orphan".

Rare diseases, including those of genetic origin, are life-threatening or chronically debilitating diseases which are of such low prevalence that special combined efforts are needed to address them. As a guide, low prevalence is taken as prevalence of less than 5 per 10,000 persons in the European Union and less than 200,000 individuals in the United States.

It is estimated that between 5,000 and 8,000 distinct rare diseases exist today, affecting between $6 \%$ and $8 \%$ of the population in total.

There are about 30 million people in the $25 \mathrm{EU}$ Countries that have a rare disease, this means that it is not so unusual as is generally believed to be, to suffer from a rare disease [1].

The focus on rare diseases is a relatively new phenomenon in Europe. Until recently, public health authorities and policy makers largely ignored them. Clearly, it is impossible to develop a public health policy specific to each rare disease. But a global rather than a piecemeal approach could provide some solutions. A global approach to 
rare diseases means that individual diseases do not fall through the net and real public health policies can be established in the areas of scientific and biomedical research, drug research and development, industry policy, information and training, social benefits, hospitalization and outpatient treatment [2].

\subsection{Health Communication on Rare Diseases}

People are becoming less accepting of a passive role as patients. The term, "Informed Patient", assumes that people with illnesses need information in order to be involved in their healthcare. This information is essential for seeking care, deciding on the best courses of action with their healthcare professionals, or for follow-through on an agreed course of treatment. However, as medicine becomes more complex, it is harder for an individual clinician to be able to provide all the information that a specific patient may need or want in order to make a decision.

Health is now reputedly the second most popular topic to be searched for on the internet. For traditionally underserved populations, the web can potentially unlock resources that could fundamentally improve health and wellbeing.

Each rare disease affects so few people that information about it may be difficult to find, making the situation even more traumatic and stressful. Before information was available on the web, families coping with a rare disease usually struggled alone. Support could only be found through telephone calls to other families suffering from similar diseases, and only if the names were provided by doctors.

Support groups such as the National Organization for Rare Disorders (NORD) have worked aggressively in the last 20 years to draw attention to people with rare diseases, and especially to draw attention to the lack of treatment options. New webbased support groups continue to proliferate. Not only are people receiving comfort from others with the same conditions, but they are learning from each other's experiences as well. By the late 1990s, most non-profit organizations had websites where people could ask questions and get immediate responses.

\subsection{Organizations on Rare Diseases in Europe and Italy}

A number of Organizations which coordinate Associations dealing with rare diseases have been set up in the past 10 years in Europe and also in Italy.

The EU, for instance, has supported several projects by EURORDIS (European Organization of Rare Diseases) which brings together more than 200 rare disease associations in 16 different Countries [3]. ORPHANET is instead a European database that deals with rare diseases and orphan drugs, with the aim of improving the diagnosis, care and treatment of patients. The database covers today about 5,000 diseases [4]. In addition, the Rare Diseases Task Force was created in January 2004 by the European Commission Public Health Directorate with the aim of advising and assisting the Directorate itself in promoting optimal prevention, diagnosis and treatment of rare diseases in Europe [5].

In Italy the National Rare Diseases Centre (CNMR, Centro Nazionale Malattie Rare) is part of the National Rare Diseases Network and carries out scientific research and public health activities, both at national and international levels. 
In particular, the CNMR has created the National Rare Diseases Register which, for each pathology, identifies the number of cases and their distribution on the national territory, being the central connection of the national clinical-epidemiological network. The National Orphan Drug Network aims at activating a surveillance system for all orphan drugs reimbursed by the National Healthcare System.

The CNMR has established several profitable collaborations on various projects with the associations of individuals affected by rare diseases. In particular, it carries out studies to evaluate the accessibility to social and health services, healthcare and the quality of life of the patients affected by rare diseases and their families.

The numerous Associations of Patients living with rare diseases play a decisive role for patients and their families. The basic principle of these Associations is reciprocal assistance: this enables the development and exchange of information and education for improved access to diagnosis, therapy, rights and patient integration.

According to the guide "Associazioni Italiane Malattie Rare" 2008-2009 edition, there are 179 Patient Associations which deal with 435 diseases.

Some Patient Associations are very small and poorly visible, often present only in one Italian region. Other Associations are much more organized and have several affiliates in Italy.

UNIAMO ONLUS is an organization founded in 1999 with the aim of having a single organism representing all Italian Patient Associations. UNIAMO presently coordinates more than 50 Associations, dealing with more than 600 different pathologies and it is part of a European network of 16 national alliances of Patient Associations, all belonging to EURORDIS organization.

\section{The Study}

\subsection{Objectives}

The purpose of the experimental survey was to draw a representative up-to-date outline of the Italian communication activities performed through the web by Patients Associations dealing with Rare Diseases.

A twofold goal was either to define a "typical" website structure (considering both contents and appearance), and/or to find recurring website categories.

Moreover, identifying both the Associations' and the patients' (that is, the websites' final users) informative and emotional needs, was also a goal to be accomplished through an experimental investigation.

The final aim of the study was to carry out a first step in planning guidelines to design effective internet sites for Patients Associations on Rare Diseases.

\subsection{Methodologies}

The experimental survey was composed of two sections: firstly, a sample of 100 Italian Associations on rare diseases was selected, to give a representative snapshot of the Italian situation.

An analysis of their websites was carried out, aiming at defining differences and similarities between the websites' structures. 
Secondly, an interview survey was done on a selection of 30 Associations, to identify the objectives of the organizations, their motivations and needs.

\subsection{Analysis of the Associations' Websites}

The analysis on the websites was completed on a sample of 100 websites of Italian Patients Associations on rare diseases. It started by the adoption of an observation grid, aimed at noticing and distinguishing the formal aspects from the content ones.

The actual structure of the grid is shown in Table 1 below.

Table 1. Sample of the websites observation grid

\begin{tabular}{|c|c|c|c|c|c|}
\hline & \multicolumn{2}{|c|}{ Content } & \multicolumn{3}{|c|}{ Formal } \\
\hline Website & $\begin{array}{l}\text { Generic } \\
\text { info }\end{array}$ & $\begin{array}{l}\text { Medical } \\
\text { info }\end{array}$ & Look\&Feel & Usability & Notes \\
\hline$\cdots$ & $\begin{array}{l}\text { Type of } \\
\text { info } \\
\text { delivered }\end{array}$ & $\begin{array}{l}\text { Type of } \\
\text { info } \\
\text { delivered }\end{array}$ & $\begin{array}{l}\text { Use and } \\
\text { quality of } \\
\text { graphics }\end{array}$ & $\begin{array}{l}\text { Efficacy, } \\
\text { efficiency, } \\
\text { ease of use }\end{array}$ & $\begin{array}{l}\text { Emotional } \\
\text { aspects }\end{array}$ \\
\hline
\end{tabular}

It was useful to identify, collect and compare the different kinds of information present in the websites (both generic and medical) and to not their different formal aspects.

Usability issues have also been considered in the formal aspects. Given that the term "usability" refers to clarity and intelligibility with which the interaction with a computer program or a website is designed, the method used in the present study was the Usability Inspection, a rapid technique for reviewing a system based on a set of guidelines. The review was conducted by two experts who were familiar with the concepts of usability in design; a systematic inspection of the user interface of the websites was thus performed to examine and judge its compliance with recognized usability principles [6]. In particular, issues such as clarity, consistency, and error minimization were analyzed establishing their contribution to global characteristics like efficacy, efficiency, ease of use.

In addition, we have also tried to identify how much informational and formal aspects were emotionally connoted. Emotional aspects were actually present in most websites, expressed both through contents and appearance (graphics, photo, videos). Emotions appeared to affect all others components, and refer to fundamental factors connected to being a patient affected by a rare disease.

\subsection{Interview Survey}

The analysis carried out through the interviews was aimed at finding in depth information on the Italian Associations' websites in order to acquire knowledge on their needs, motivations and expectances on the basis of their direct experiences.

Thirty telephone-based interviews were conducted by 3 researchers who worked in parallel, interviewing Associations' representatives from different places in Italy. Nearly all the Italian regions were present in the sample. 
In almost all cases, the interviewee was the President of the Association, generally a patient her/himself or a patient's relative.

The interview was divided into 3 sections. The first one aimed at gathering general information on the website, while the second one was essentially focused on finding out its main objective, the target users, the Associations' motivations and needs, and their communication strategies.

The third section was devised to gather information on how the Association support patients and their families through the website.

\section{The Results}

\subsection{Websites Analysis}

The websites analysis is synthetically shown in Table 2 below.

Contents appear to be quite homogeneous in kind and quantity all over the sites; as a matter of fact, all websites contain essentially the same typologies of general information:

- The history of the Association, information about its offices and contacts, its activities

- Demand for financial support, donations

- Legal information about rare diseases and conveniences granted to patients

- Events, initiatives

- Other: contacts, links, downloads...

A certain uniformity is also observed with regards the medical/scientific section, since a few classes of information recur in a high percentage of the monitored websites:

- A description of the pathology (causes, symptoms, consequences)

- Research: state of the art of medical research concerning the pathology

- Prevention and Therapy: information about care centres, available drugs etc.

Relatively low percentages of Associations do offer on-line support and services to users, such as:

- Medical support

- Psychological support

These are classified as "services" since they require an interaction between doctors/psychologists and patients/relatives.

A higher diffusion is found for some tools, like:

- Forums and communities, where users can register and exchange suggestions, information, feelings...

- Message boards, where users can write messages, impressions about the site, ask questions to other people, in a public and real-time space

- FAQ: Answers to Frequently Asked Questions, collected for a quick response

- Advice for dealing with frequent difficulties in everyday life.

- Newsletter and Reviews.

- Other tools, for example: chat, guestbook... 
Table 2. Synthesis of results emerged in websites analysis

\begin{tabular}{|c|c|c|c|}
\hline CATEGORY & SUB-CATEGORY & ITEM & $\%$ \\
\hline \multirow{15}{*}{ Content } & \multirow{4}{*}{$\begin{array}{l}\text { General informa- } \\
\text { tion }\end{array}$} & Association & 98 \\
\hline & & Funding & 98 \\
\hline & & Legal info & 89 \\
\hline & & Events & 75 \\
\hline & \multirow{3}{*}{$\begin{array}{l}\text { Scientific informa- } \\
\text { tion }\end{array}$} & Disease description & 85 \\
\hline & & Research & 38 \\
\hline & & Prevention/Therapy & 37 \\
\hline & \multirow{2}{*}{ Services } & Medical support & 7 \\
\hline & & Psychological support & 3 \\
\hline & \multirow{6}{*}{ Tools } & Forum/Community & 28 \\
\hline & & Message board & 5 \\
\hline & & FAQs & 8 \\
\hline & & Advises for everyday life & 25 \\
\hline & & Newsletter/Review & 17 \\
\hline & & Other & 5 \\
\hline \multirow{10}{*}{ Form } & \multirow{6}{*}{ Usability } & Easy to use & 25 \\
\hline & & Improvable & 34 \\
\hline & & Not usable & 40 \\
\hline & & Familiar language & 58 \\
\hline & & Formal language & 40 \\
\hline & & Translation & 5 \\
\hline & \multirow{4}{*}{ Look\&Feel } & Sophisticated graphics & 43 \\
\hline & & "Home made" graphics & 55 \\
\hline & & Photos/Videos & 48 \\
\hline & & Images & 35 \\
\hline
\end{tabular}

The second extensive section of the analysis took into consideration the formal aspects of websites, that is: Usability and look\&feel.

As for usability, a website has been judged i) usable, ii) improvable, or iii) not usable. In addition, other aspects, such as the adoption of the user's language and the possibility to obtain a translated version of the site, have been taken into account.

The observation of the look\&feel focused on features like:

- Graphics, in order to define whether a sophisticated or a "home made" look had been produced

- Presence of photos and/or videos

- Use of images, drawings, animation .

Third, and last, a parameter of this part of the study, dedicated to websites, was the Emotion. In particular, the presence of a relational attitude of the Associations towards the users was detected, together with the tendency to realize an affective approach to communication. 
Affective aspects are obviously crosswise, and they are detectable both in the contents and in the form. More specifically, it is possible to notice an emotional factor in:

- The way contents are expressed (language, examples, focus), the attitude towards the user (addressing him as a simple reader or as a patient/ concerned person)

- The kind of contents included (stories on patients' experiences, narratives, poems)

- The use of images, photographs, videos aimed at arousing emotion, empathy, care.

\subsection{Description of the Interviews Results}

The interviews analysis clearly showed that in most cases the websites of the Associations on rare diseases have been created along with the association itself, or a few years later if the Association was founded in the early 1990's. Generally, the promoter is the patient her/himself or a close relative, but in some cases even physicians and researchers cooperate to the setting up of the Associations.

Mostly the sites have been developed by the patients themselves, family members or friends with the technical advice of a web design expert.

The contents concerning general information, disease regulation and policy, activities, events, fund raising, are decided by the President of the Association or by the management team, with the support of physicians and medical specialists as far as the scientific contents are concerned.

Except for one case, all the sites of our sample are updated by volunteers on the average once a week; or in any case, whenever there is a new content to include.

In all the cases, the Associations pay special attention to patients and their families, informing and educating them on the pathology, helping them protect their social rights and providing them with an affective and psychological support, as well as, in some cases, actual practical aid.

Among others, a significant help that the site can offer is to try to create a network aimed at supporting people affected, improving health and psychological care and putting in touch persons with the same experience. People sharing the same condition, even if afar, appear willing to communicate, comparing their lives and their emotions, offering solidarity, supporting each other and exchanging information on how to solve the problems of daily life.

One interviewee, President of an Association and a patient herself, said that the site is the best way to communicate and disseminate knowledge on orphan diseases in order to avoid that other people should feel a sense of isolation, loneliness and fear of the unknown.

The Associations are often addressed to the medical community as well, especially to paediatricians, family doctors, health care facilities, caregivers, researchers and medical school final-year students. The importance is underlined of promoting scientific research, organizing and participating in conferences, seminars, workshops and fund grant research. With regard to education, the website should be a way to bring physicians and health care staff up to date and make them aware of orphan diseases in a global approach. 
By reason of the lacking interoperability among different health care and health research centres, another strong point of the Associations' websites is to avoid that those centres make use of the patients on behalf of the centres themselves. So the website is also a way for the patient to become aware of the disease and to be free to choose among different possibilities of health care facilities.

In quite all the cases, fund raising is considered highly important by the Associations but it comes last on the list, after the needs of information, support, research and education. Anyway, Associations are generally very lively, organizing social events such as concerts, festivals, dinners, all aimed at collecting money for the Association itself and to promote research.

The communication strategies of the Associations' sites rely mainly on in depth information on scientific contents, their accuracy and reliability, but also on the simple way to express them, trying to make themselves understood by everyone.

An effort of the Association that is reflected in the website is to provide services such as forums, mailing lists or simply a phone contact, in order to give support and create a network of people with the same experience. Nevertheless, it would be enough to provide information on any service given in the local area or far away.

To foster a relationship among patients and medical specialists and to create a network among families and health care centres is judged to be crucial and of the greatest importance.

\section{Discussion and Design Hints}

The study showed that it is possible to classify the websites into two different categories, depending on the communication strategy of the correspondent Association.

Some websites are likely to be defined "institutional", for they show a complex graphic aspect (a coordinate-image, with the Association's logo), and do contain scientific information, aseptic data for generic users. They seem to address non-specific users, potential contributors or volunteers, more then patients or patient's relatives.

The other kind of websites appears more "relational". They show an inclination towards patients and families, expressed through a spontaneous graphic asset, a familiar language, patient-centred contents. The use of photos, images, drawings and narratives highlights the value assigned to emotional aspects, human relationships, empathy among sufferers and families, understanding the emotional distress and the patients' physical suffering. This finding is also noticed through the interview-survey, for all the interviewed Association representatives stressed the primary importance of giving psychological support and expressing empathy and affective involvement with sufferers and their families.

Taken together, the websites analysis and the interviews suggested some guidelines (listed in Table 3, below) to develop more efficient and effective websites for rare diseases Associations, with regard to the kind of contents and their form, the tools provided, usability and accessibility, emotional supports [7].

Internet is a very important channel to disseminate the available knowledge about orphan diseases because an early diagnosis and adequate care can reduce drastically 
Table 3. Guidelines for designing websites

\begin{tabular}{l}
\hline Contents about the pathology \\
\hline Medical/scientific/ information \\
\hline Communication about the research \\
\hline Regulation and policy \\
\hline Information about drugs \\
\hline Advice for everyday life \\
\hline Health education at a specific and a global level \\
\hline Information about the Association \\
\hline Association description, involved people and contacts \\
\hline Legal information \\
\hline Activities and events \\
\hline Fund raising \\
\hline Information about healthcare facilities \\
\hline Local, National and International research and healthcare centers, \\
hospitals \\
\hline Psychological counseling \\
\hline Content form \\
\hline providing correct, complete, reliable and up-to-date scientific \\
publications; \\
\hline making use of a simple standard of language in expressing contents; \\
\hline Tools \\
\hline Forum/Community \\
\hline On-line expert \\
\hline FAQs \\
\hline Message boards \\
\hline Newsletters or Reviews \\
\hline Usability and accessibility \\
\hline Consistency \\
\hline Visual clarity \\
\hline Compatibility \\
\hline Informative feedback \\
\hline Explicitness \\
\hline English version \\
\hline Protional support (crosswise) \\
\hline Creating a network of patients, families, associations and health care \\
\hline Providing information on activities and events \\
\hline andinges \\
\hline
\end{tabular}

impairments and life-threatening aspects for these kinds of pathologies. As the Rare diseases Associations websites are so important for all the persons involved, we have to take into account how to express all the potentialities of this tool.

Acknowledgments. The Authors are grateful to all the Associations Representatives for their important help and contribution. 


\section{References}

1. Rare diseases: Understanding this Public Health Priority. Eurordis, http: / /www. eurordis.org

2. European Commision: Public Health - Rare Diseases, http: / / ec.europa.eu/health/ph_threats/non_com/ rare_diseases_en.htm

3. EURORDIS, http: //www. eurordis.org

4. ORPHANET, http: //www. orpha . net

5. European Commission: Rare Diseases Task Force, http://ec.europa.eu/health/ph_information/implement/wp/ morbidity/rdtf_en.htm

6. Nielsen, J., Mack, R.L.: Usability Inspection Methods. John Wiley \& Sons, New York (1994)

7. Nielsen, J.: Designing Web Usability. New Riders Publishing, Indianapolis (2000) 